\title{
Penerapan Inverse Manufacturing dalam Penanganan Produk Lampu Hemat Energi
}

\author{
Romy Loice ${ }^{1}$, Bagus Made Arthaya ${ }^{2}$, Harry Prasetyo ${ }^{3}$ \\ 123) Jurusan Teknik Industri Fakultas Teknologi Industri, Universitas Katolik Parahyangan , \\ Jl. Ciumbuleuit 94, Bandung 40141 \\ romy.loice@unpar.ac.id, bagusmooidgmail.com, hrrprasetyo@gmail.com
}

\begin{abstract}
Lighting is one of the human basic needs that must be fullfiled. Compact fluorescent lamps is the most used lamp as source of lighting. However, they contain mercury, which is classified as heavy metals, that can potentially harm the environment. Even as mercury container, many people didn't know that. Many people don't know the method to handle the broken or used compact fluorescent lamp. They just dispose the broken compact fluorescent lamp to trash without considering the effect of mercury contained.
\end{abstract}

Inverse Manufacturing concept is about designing product life cycle that aims to repair and reuse product components so that the negative impact can be reduced and minimized. In this research, the concept of Inverse Manufacturing is applied on handling the compact fluorescent lamp product in Bandung, West Java. The study is begun with designing the Inverse Manufacturing concepts model by adding the step of collecting back (two scenarios), sorting, repairing, remanufacturing, and recycling into the life cycle of compact fluorescent lamp. The results of recycling rates of 15 Watt compact fluorescent lamp (about 234 grams) starts from the lowest value, and the maximum value are $27,51 \%$ (64,366 grams), and 27,61\% $(64,609$ grams). By applying this concept, the result are the reduction on the amount of compact fluorescent lamp waste dumped into the environment and the achievement of the conservation of natural resources through the reuse of used components.

\begin{abstract}
Abstrak
Sumber penerangan merupakan salah satu dari banyak kebutuhan yang harus dipenuhi oleh manusia. Jenis lampu yang sering digunakan sebagai sumber penerangan adalah lampu hemat energi. Komponen di dalam lampu hemat energi ternyata memiliki potensi untuk merusak lingkugan, karena kandungan merkuri yang ada dalam lampu tergolong logam berat dan beracun. Saat ini, pola penanganan masyarakat untuk lampu hemat energi pasca pakai belum tepat, yaitu langsung membuang ke tempat sampah.

Konsep Inverse Manufacturing merupakan perancangan siklus hidup suatu produk yang bertujuan untuk memperbaiki dan memanfaatkan kembali komponen produk pasca pakai agar efek negatif yang ditimbulkan terhadap lingkungan berkurang. Pada penelitian ini, konsep Inverse Manufacturing diterapkan dalam penanganan produk lampu hemat energi pasca pakai untuk wilayah Bandung, Jawa Barat. Penelitian ini dimulai dengan merancang model konsep Inverse Manufacturing yang meliputi tahap pengumpulan kembali (dua skenario), pemilahan, perbaikan, remanufaktur, dan daur ulang. Persentase hasil perhitungan tingkat daur ulang lampu hemat energi 15 Watt (234 gram) mulai dari nilai terendah dan maksimum berturut turut sebesar 27,51 $\%$ (64,366 gram) dan 27,61 \% (64,609 gram). Dengan penerapan konsep Inverse Manufacturing ini akan menghasilkan pengurangan jumlah sampah lampu yang dibuang ke lingkungan dan dapat tercapainya konservasi sumber daya alam melalui pemanfaatan kembali komponen pasca pakai.

Kata Kunci: Inverse Manufacturing, Lampu Hemat Energi, Merkuri, Siklus Hidup, Tingkat Daur Ulang
\end{abstract}




\section{Pendahuluan}

Salah satu kebutuhan manusia adalah sumber penerangan. Sumber penerangan yang sering digunakan adalah lampu hemat energi. Lampu hemat energi merupakan bentuk sederhana atau praktis dari lampu neon konvensional (Sasaki, 1994). Dibalik kegunaannya yang sangat membantu dalam hal penerangan, produk ini mengandung merkuri dalam jumlah tertentu tergantung merk dan produsennya (Li \& Jin, 2011). Dalam lampu hemat energi dengan daya 15 Watt terdapat merkuri dengan kadar $4 \mathrm{mg}$ (Scholand \& Dillon, 2012). Senyawa merkuri dapat memberikan dampak buruk bagi kesehatan tubuh manusia dan dapat merusak ekosistem (Clarkson, Magos, dan Myers, 2003).

Pola penanganan lampu hemat energi yang tidak tepat dapat menimbulkan dampak negatif bagi masyarakat dan lingkungan. Secara umum, sampah lampu yang sudah habis masa pakainya langsung dibuang ke tempat sampah. Hal ini meningkatkan risiko terjadinya pelepasan merkuri ke lingkungan.

Saat ini, belum terlihat peran dan tanggung jawab perusahaan yang memproduksi lampu hemat energi dalam keikutsertaan penanganan produk lampu pasca pakai. Untuk itu diperlukan penerapan konsep Inverse Manufacturing bagi perancangan siklus hidup dari lampu hemat energi secara keseluruhan agar pada saat produk ini mencapai tahap pasca pakainya dapat ditangani dengan pola yang tepat.

Inverse Manufacturing merupakan suatu konsep yang ditujukan untuk mendesain siklus hidup suatu produk secara keseluruhan mulai dari konsep awal produk sampai tahapan penggunaan kembali (Kimura, 1999). Inverse Manufacturing merupakan sebuah proyek lanjutan dari penggunaan kembali, daur ulang, dan remanufaktur dari suatu produk yang diterapkan di negara Jepang. Konsep Inverse Manufacturing memiliki fokus pada tahap sebelum berjalannya proses manufaktur, yaitu pada tahap desain produk. Tujuan utama dari konsep ini adalah untuk memperpanjang daur hidup dari sebuah produk dengan desain fitur yang memiliki kemampuan untuk diolah kembali dan di daur ulang (Madu, 2004).

\section{Metode Penelitian}

Penelitian ini dilakukan dalam beberapa tahapan, yaitu:

1. Evaluasi sistem awal.
Pada tahapan ini, dilakukan identifikasi siklus hidup lampu hemat energi yang terjadi saat ini, khususnya di kota Bandung, dengan cara observasi, dan penyebaran kuesioner ke responden pengguna lampu hemat energi. Pada tahapan ini, dilakukan juga identifikasi peluang penerapan konsep inverse manufacturing dengan memperhatikan komponen-komponen yang ada dalam lampu hemat energi dan cara kerjanya., Untuk mendapatkan peluang tersebut, dilakukan juga wawancara dengan aktivis lingkungan.

2. Usulan penerapan konsep inverse manufacturing.

Pada tahap ini dilakukan perancangan siklus hidup usulan dari produk lampu hemat energi sesuai dengan konsep inverse manufacturing, yaitu menciptakan closed-loop system pada daur hidup produk. Closedloop system ini berarti membuat rantai ekstraksi, produksi, penggunaan, dan disposal menjadi suatu siklus tertutup. Produk lampu hemat energi juga diusulkan produk modular dengan memperhatikan jenis kerusakan yang umumnya terjadi pada lampu hemat energi. Pada sebagian tahapan siklus hidup usulan yang merupakan tahapan baru dibandingkan siklus hidup awal, dilakukan usulan proses ataupun skenario yang dilakukan pada tahapan tersebut. Proses lanjutan dari setiap komponen lampu pasca rusak juga ditentukan dengan cara penggolongan komponen pada kategori dapat digunakan kembali atau didaur ulang.

3. Evaluasi konsep usulan.

Konsep usulan berupa rancangan siklus hidup produk dievaluasi dengan melakukan perhitungan tingkat daur ulang produk lampu hemat energi setelah diterapkan konsep inverse manufacturing.

\section{Hasil dan Pembahasan}

Siklus hidup lampu hemat energi dimulai dari tahap ekstraksi material, manufaktur, penggunaan, dan disposal. Dari hasil wawancara dan kuesioner yang disebarkan kepada 103 responden pengguna lampu hemat energi di Bandung, diketahui bahwa 94 responden langsung membuang ke tempat sampah, sisanya melakukan pembakaran, dikembalikan ke tempat pembelian, dan digunakan kembali untuk keperluan lain. Tidak ada penanganan lebih lanjut pada lampu hemat energi pasca pakai. 
Tata cara penanganan lampu hemat energi yang rusak atau sudah habis masa gunanya juga tidak tercantum dalam kotak kemasan. Sebagian besar responden juga tidak mengetahui bahwa lampu hemat energi mengandung senyawa merkuri (81 orang dari total 103 responden).

Peranan pemerintah juga diperlukan dalam hal pemberian himbauan, penyediaan sarana prasana pendukung pengolahan limbah lampu hemat energi, serta menjalankan regulasi mengenai pengelolaan limbah elektronik. Himbauan pemerintah saat ini tentang bahaya yang terkandung di dalam limbah elektronik, khususnya lampu hemat energi masih sangat kurang. Masih banyaknya masyarakat yang kurang memperhatikan bahaya limbah lampu sehingga berdampak pada pembuangan tanpa tata cara yang benar menjadi salah satu bukti. Regulasi mengenai penanganan dan bahaya limbah elektronik sudah ditetapkan, namun peraturan tersebut kurang diterapkan pada kondisi nyata, sebagai contoh tidak adanya larangan keras atau denda serta pengawasan langsung dari pihak pemerintah bagi mereka yang membuang limbah lampu hemat energi secara langsung ke lingkungan tanpa adanya penanganan khusus. Untuk wilayah kota Bandung, belum terdapat sistem yang mengatur bagaimana penanganan yang tepat untuk sampah lampu hemat energi.

Scholand dan Dillon (2012) menyebutkan kandungan merkuri dalam lampu hemat energi 15 Watt sebesar $4 \mathrm{mg}$. Jika diasumsikan untuk semua lampu hemat energi dengan variasi daya yang berbeda-beda memiliki jumlah merkuri yang sama, yaitu $4 \mathrm{mg}$, dapat dihitung ekspektasi total tersebarnya merkuri di Kota Bandung akibat pola penanganan yang tidak tepat sebesar 2,3 $\mathrm{kg}$ untuk setiap bulannya. Apabila pola penanganan tidak tepat ini berlangsung secara terus menerus maka kemungkinan besar terjadinya proses akumulasi merkuri yang tersebar di tanah Kota Bandung dapat melebihi nilai ambang batas yang sudah ditentukan yaitu, 0,3 0,5 ppm (Mirdat, Patadungan, \& Isrun, 2013).

Sebelum merancang pola penanganan produk lampu hemat energi yang tepat, dilakukan pengelompokan komponen berdasarkan material logam, nonlogam, dan gas yang dapat dilihat pada Tabel 1.

Dari proses identifikasi peluang penerapan inverse manufacturing, diperoleh adanya peluang pemanfaatan lampu hemat energi pasca pakai. Pemanfaatan tersebut bisa dilakukan karena umumnya kerusakan lampu biasanya hanya pada komponen elektronik sedangkan komponen bulb masih baik atau kebalikannya.
Tabel 1: Pengelompokan komponen

\begin{tabular}{|c|c|c|}
\hline Logam & Non-Logam & Gas \\
\hline $\begin{array}{l}\text { Screw shell (Base) } \\
* \text { ) }\end{array}$ & $\begin{array}{ll}\text { Housing } & \text { top } \\
\left.(\text { Base })^{*}\right)\end{array} \quad$. & $\begin{array}{l}\text { Argon } \\
\left.\text { lengkap })^{*}\right)\end{array}$ \\
\hline $\begin{array}{l}\text { Transformer (EB) } \\
\left.{ }^{*}\right)\end{array}$ & $\begin{array}{l}\text { Housing bottom } \\
\left.(\text { Base })^{*}\right)\end{array}$ & $\begin{array}{ll}\text { Neon } & (\mathrm{Pe}- \\
\text { lengkap })\end{array}$ \\
\hline Induktor $(\mathrm{EB})^{*}$ ) & Bulb $\left.^{*}\right)$ & $\begin{array}{l}\text { Hidrogen } \\
\text { (Pelengkap) }\end{array}$ \\
\hline Dioda $(\mathrm{EB})^{*}$ ) & $\begin{array}{ll}\text { Papan } & \text { sirkuit } \\
(\mathrm{EB}) & *\end{array}$ & $\begin{array}{l}\text { Oksigen } \\
\text { lengkap })\end{array}$ \\
\hline Kapasitor EB) ${ }^{*}$ ) & $\begin{array}{l}\text { Kotak kemasan } \\
\left(\text { Pelengkap) }{ }^{*}\right)\end{array}$ & $\begin{array}{ll}\text { Nitrogen } & (\mathrm{Pe}- \\
\text { lengkap }) & \end{array}$ \\
\hline Transistor $(\mathrm{EB}){ }^{*}$ ) & $\begin{array}{l}\text { Lem resin (Pe- } \\
\left.\text { lengkap) }{ }^{*}\right)\end{array}$ & \\
\hline Resistor $(\mathrm{EB})^{*}$ ) & & \\
\hline Elektrode $^{*}$ ) & & \\
\hline $\begin{array}{l}\text { Merkuri } \\
\left.\text { lengkap })^{*}\right)\end{array}$ & & \\
\hline $\begin{array}{l}\text { Solder paste (Pe- } \\
\left.\text { lengkap) }{ }^{*}\right)\end{array}$ & & \\
\hline $\begin{array}{l}\text { Yttrium (di dalam } \\
\text { Bulb) }{ }^{*} \text { ) }\end{array}$ & & \\
\hline $\begin{array}{l}\text { Europium (di } \\
\left.\text { dalam Bulb })^{*}\right)\end{array}$ & & \\
\hline
\end{tabular}

Usulan penanganan produk lampu hemat energi berdasarkan konsep Inverse Manufacturing dapat dilihat pada Gambar 1. Terlihat adanya penambahan tahapan dalam siklus hidup lampu berupa pengumpulan kembali, pemilahan, inspeksi, perbaikan, remanufaktur, daur ulang, pemanfaatan untuk keperluan lain, dan pembuangan akhir.

Setelah tahap penggunaan di konsumen akhir selesai, lampu hemat energi akan dikumpulkan kembali dari konsumen untuk dibawa dan diolah oleh pihak produsen maupun pabrik daur ulang. Penelitian ini menghasilkan dua skenario untuk tahapan pengumpulan kembali ini.

Skenario pertama melibatkan tingkat RT/RW yang berada di Kota Bandung untuk mengumpulkan sampah lampu. Setelah itu, Dinas Kebersihan Kota Bandung akan mengambil sampah lampu di setiap RT/RW untuk dikumpulkan di Tempat Pembuangan Akhir (TPA). Berikutnya, Dinas Kebersihan akan menyampaikan informasi kepada pihak produsen atau pabrik daur ulang untuk mengambil sampah lampu yang sudah dikumpulkan di TPA.

Skenario pengumpulan yang kedua melibatkan pihak retailer resmi yang bekerja sama dengan produsen lampu sebagai tempat pengumpulan kembali sampah lampu dari konsumen. Selain itu, skenario ini menggunakan insentif sebagai salah satu pemicu peran aktif masyarakat dalam mengumpulkan kembali sampah lampu.

Setelah sampai di produsen atau pabrik daur 
ulang, sampah lampu masuk dalam tahap pemilahan. Tahap ini akan membagi lampu hemat hemat energi menjadi tiga buah komponen besar, yaitu bulb, electronic ballast, dan base. Tujuan dari pemilahan ini adalah mempermudah tahap inspeksi.

Tahap inspeksi merupakan proses penentuan komponen akan memasuki tahap perbaikan dan remanufaktur atau tahap daur ulang. Komponen yang memiliki kerusakan minor (masih memenuhi standar baik dari fungsi dan estetika) akan diperbaiki untuk digunakan kembali pada proses remanufaktur. Sedangkan komponen yang mengalami kerusakan mayor (sudah tidak dapat diperbaiki) akan masuk ke tahap daur ulang untuk dilebur menjadi material dasar.

Komponen yang lolos inspeksi dan masih memenuhi standar baik dari segi fungsi maupun estetika akan masuk ke dalam tahap perbaikan untuk diperbaiki kemudian dilanjutkan dengan tahap remanufaktur. Dengan adanya perbaikan dan penggunaan kembali dari komponen pasca pakai secara tidak langsung terjadi penghematan dari segi penggunaan sumber daya alam baru dan dari segi konsumsi energi yang digunakan untuk memproduksi lampu hemat energi yang baru. Gambar 2 menunjukan aliran komponen pada proses perbaikan dan remanufaktur

Tahap daur ulang merupakan proses meleburkan komponen pasca pakai yang sudah tidak dapat digunakan kembali menjadi material dasar. Gambar 3 menunjukan proses pengambilan senyawa merkuri dari lampu hemat energi.

Dari dalam komponen bulb dapat diambil juga bubuk pelapisnya untuk digunakan kembali sebagai bahan baku produksi (lihat Gambar 4).

Komponen housing yang rusak dapat didaur ulang dengan melewati beberapa proses, yaitu cutting, shredding, dan agglomeration (Lardinois \& Klundert, 1995). Serpihan kaca dari komponen bulb dapat didaur ulang dengan cara melelehkannya pada suhu $1540^{\circ} \mathrm{C}$ (Williams, 2005). Untuk komponen screw shell, solder paste dan elektrode didaur ulang dengan melelehkan sampai titik lebur masing-masing (Williams, 2005). Untuk kotak kemasan proses daur ulang bermula dari proses menjadikan bubur kertas, pemisahan dari kontaminan, kemudian pengentalan bubur kertas (Williams, 2005). Tingkat daur ulang satu buah lampu hemat energi dengan daya 15 Watt dapat dihitung berdasarkan data Scholand \& Dillon (2012). Tabel 2 menunjukkan material penyusun lampu hemat energi 15 Watt.

Berdasarkan perhitungan tersebut didapat
Tabel 2: Material penyusun lampu 15 Watt

\begin{tabular}{|c|c|c|}
\hline Komponen & Material & Massa (g) \\
\hline & Europium & 0,001 \\
\hline Housing & $\begin{array}{l}\text { Polyethylene Tereptha- } \\
\text { late (PET) }\end{array}$ & 2,39 \\
\hline \multirow[t]{3}{*}{ Screw Shell } & Cast Iron & 0,029 \\
\hline & Kromium & 0,0002 \\
\hline & Aluminium Oksida & 0,008 \\
\hline \multirow[t]{4}{*}{ Elektrode } & Timbal & 0,19 \\
\hline & Tembaga & 0,402 \\
\hline & Nikel & 0,003 \\
\hline & Kuningan & 1,65 \\
\hline Electronic Ballast & Semikonduktor & 127,268 \\
\hline Papan Sirkuit & Printed Wiring Board & 3,7 \\
\hline \multirow{12}{*}{ Pelengkap } & Merkuri & 0,004 \\
\hline & Gas Argon & 0,004 \\
\hline & Gas Nitrogen & 0,119 \\
\hline & Gas Oksigen & 0,159 \\
\hline & Gas Hidrogen & 0,002 \\
\hline & Gas Neon & 0,0004 \\
\hline & Amonia & 0,13 \\
\hline & Gas Neon & 0,0004 \\
\hline & Amonia & 0,13 \\
\hline & Asam Nitrik & 7,9 \\
\hline & Asam Sulfur & 1,67 \\
\hline & Lem Resin & 4,5 \\
\hline Pelengkap & Solder Paste & 0,3 \\
\hline Kotak Kemasan & Corrugated Board & 81 \\
\hline Total Massa & & 234 \\
\hline
\end{tabular}

rentang tingkat daur ulang lampu hemat energi antara $27,51 \%$ sampai $27,61 \%$. Untuk keperluan evaluasi penerapan inverse manufacturing ini, dilakukan perhitungan tingkat daur ulang dengan menggunakan nilai minimum dan nilai maksimum. Tabel 3 sampai Tabel 4 menunjukan perhitungan tingkat daur ulang lampu secara berturut turut dari nilai minimum sampai nilai maksimum.

Diperoleh estimasi massa hasil daur ulang adalah 64.366 sampai dengan 64.609 gram per setiap lampu hemat energi yang melalui inverse manufacturing hasil penelitian ini. Nilai tingkat daur ulang dari produk lampu hemat energi ini merepresentasikan pengurangan jumlah sampah lampu yang dibuang ke lingkungan, dalam artian adanya proses pemanfaatan kembali dari komponen komponen pasca pakai untuk keperluan proses remanufaktur. Tujuan dari perhitungan tingkat daur ulang produk lampu hemat energi merupakan salah satu upaya dalam mencapai Zero Waste dalam konsep Inverse Manufacturing.

Pengecekan dan pengawasan dari berjalannya rencana penanganan produk lampu hemat energi berdasarkan konsep Inverse Manufacturing dapat dilihat dari beberapa aspek. Pertama, pengecekan dapat dilihat dari jumlah penumpukan sampah lampu. 


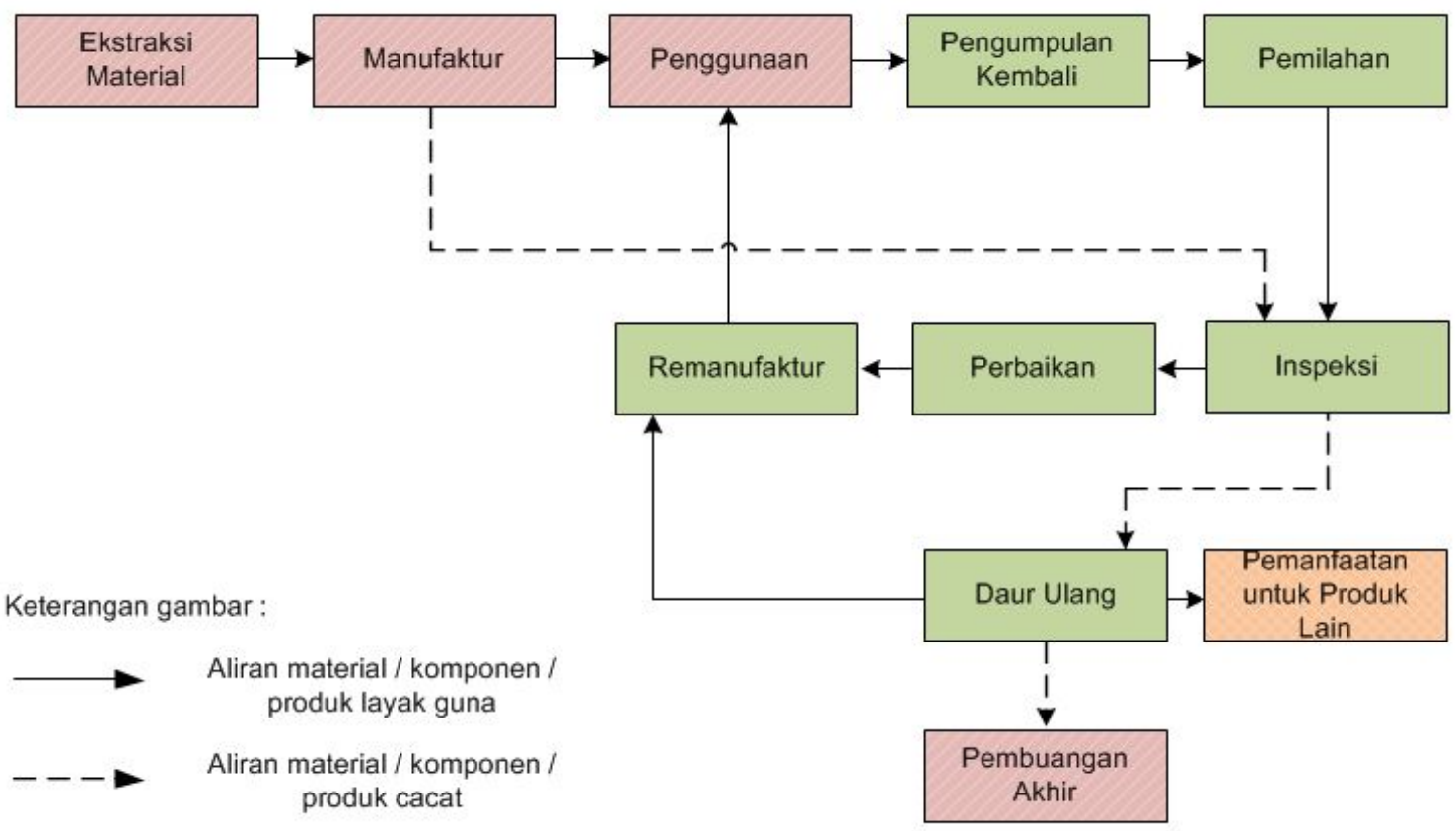

Gambar 1: Usulan penanganan lampu hemat energi berdasarkan konsep Inverse Manufacturing

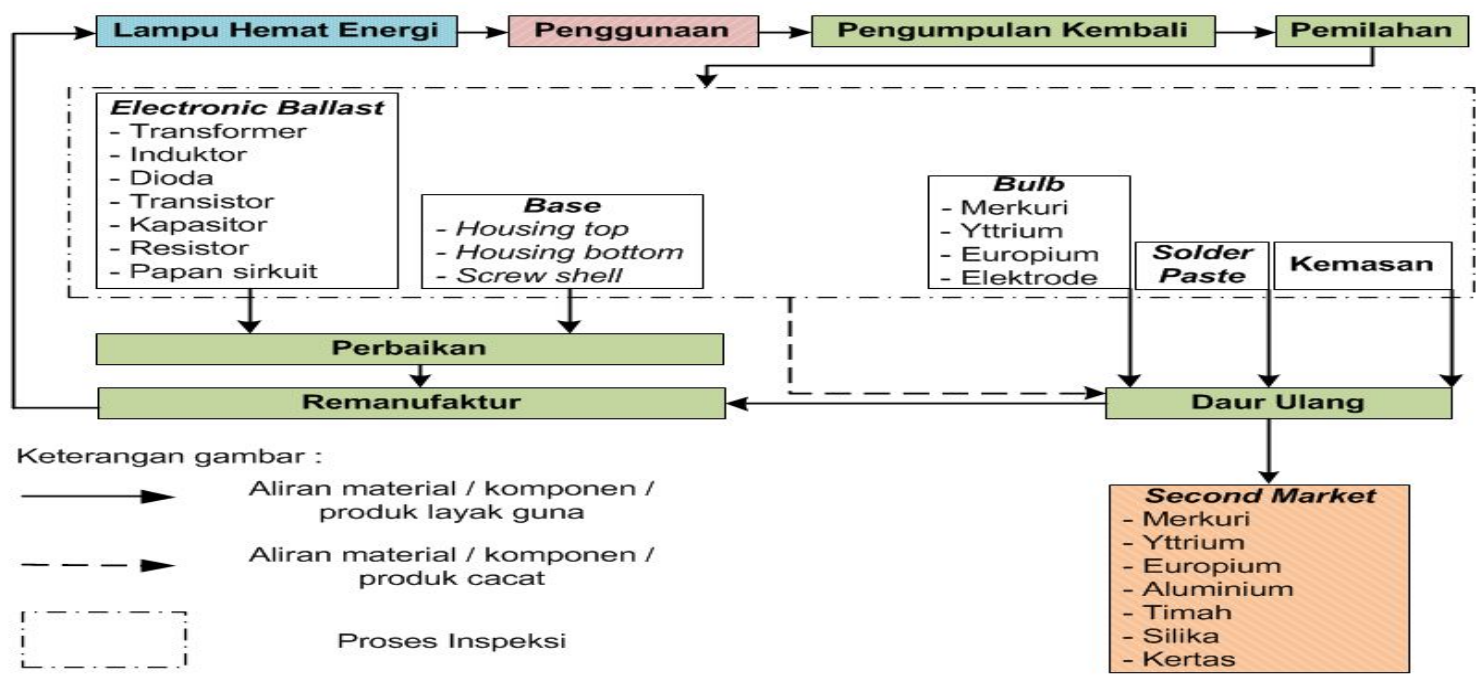

Gambar 2: Aliran komponen pada proses perbaikan dan remanufaktur 
Tabel 3: Tingkat Daur Ulang Minimum

\begin{tabular}{|c|c|c|c|}
\hline Material & Massa(g) & $\begin{array}{c}\text { Tingkat Daur } \\
\text { Ulang }(\%)\end{array}$ & $\begin{array}{c}\text { Estimasi } \\
\text { Massa } \\
\text { Hasil Daur } \\
\text { Ulang }(\mathrm{g})\end{array}$ \\
\hline Kaca & 1,2 & 23,7 & 0,284 \\
\hline Yttrium & 1,37 & 0,1 & 0,001 \\
\hline Europium & 0,001 & 0,1 & 0,000001 \\
\hline $\begin{array}{l}\text { Polyethylene } \\
\text { Terepthalate } \\
\text { (PET) }\end{array}$ & 2,39 & 30 & 0,717 \\
\hline Cast Iron & 0,029 & 51 & 0,015 \\
\hline Kromium & 0,0002 & 51 & 0 \\
\hline $\begin{array}{l}\text { Aluminium } \\
\text { Oksida }\end{array}$ & 0,008 & 51 & 0,004 \\
\hline Timbal & 0,19 & 51 & 0,097 \\
\hline Tembaga & 0,402 & 51 & 0,205 \\
\hline Nikel & 0,003 & 51 & 0,002 \\
\hline Kuningan & 1,65 & 51 & 0,842 \\
\hline Semikon & 127,268 & - & - \\
\hline duktor & & & \\
\hline $\begin{array}{c}\text { Printed Wiring } \\
\text { Board }\end{array}$ & 3,7 & - & - \\
\hline Merkuri & 0,004 & 1 & 0,00004 \\
\hline Gas Argon & 0,004 & - & - \\
\hline Gas Nitrogen & 0,119 & - & - \\
\hline Gas Oksigen & 0,159 & - & - \\
\hline Gas Hidrogen & 0,002 & - & - \\
\hline Gas Neon & 0,0004 & - & - \\
\hline Amonia & 0,13 & - & - \\
\hline Asam Nitrik & 7,9 & - & - \\
\hline Asam Sulfur & 1,67 & - & - \\
\hline Lem Resin & 4,5 & - & - \\
\hline Solder Paste & 0,3 & 51 & 0,153 \\
\hline $\begin{array}{l}\text { Corrugated } \\
\text { Board }\end{array}$ & 81 & 76,6 & 62,046 \\
\hline Total Massa & 234 & & 64,366 \\
\hline
\end{tabular}

Pengurangan jumlah penumpukan jumlah sampah lampu di Tempat Pembuangan Akhir (TPA) mengindikasikan bahwa rencana penanganan ini berhasil diterapkan, semakin sedikitnya jumlah sampah lampu di TPA menandakan produk lampu pasca pakai tidak langsung dibuang melainkan dilakukan aktivitas pengumpulan dan pemanfaatan kembali.

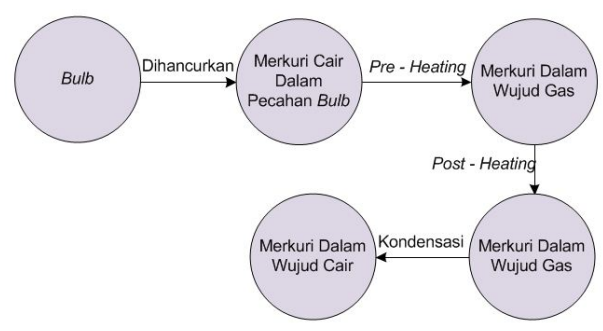

Gambar 3: Alur proses pengambilan merkuri (Sumber : diadaptasi dari Chang, You, Yu, Chen, \& Chiu dalam Tunsu, Retegan, \& Ekberg, 2011)

Kedua, pengecekan dapat dilakukan pada tahap atau proses pengumpulan kembali. Setiap produsen memiliki data jumlah produksi dan penjualan lampu hemat energi. Data dari produsen ini juga didukung data dari retailer yaitu data terkait penjualan lampu hemat en-

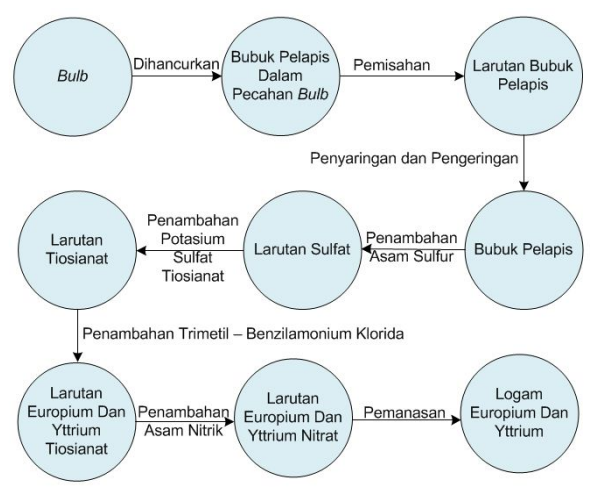

Gambar 4: Alur proses pengambilan bubuk pelapis (Sumber: Rabah dalam Tunsu, Retegan, \& Ekberg, 2011)

ergi ke konsumen. Dengan data dari kedua sumber ini, produsen dapat mengecek jumlah lampu hemat energi pasca pakai yang seharusnya dikembalikan kepada mereka. Apabila jumlah lampu yang terjual sama dengan jumlah lampu yang dikumpulkan maka hal ini mengindikasikan tidak adanya perilaku pembuangan lampu pasca pakai secara langsung ke tempat sampah atau TPA. Apabila terjadi penurunan atau bahkan jumlah lampu pasca pakai yang dikumpulkan ternyata masih sedikit, proses yang perlu diperbaiki dalam hal ini adalah proses pengumpulan kembali. Untuk meningkatkan jumlah lampu yang dikumpulkan, produsen bersama retailer saling bekerja sama untuk mendorong perilaku konsumen mengembalikan lampu pasca pakainya. Hal ini juga dapat didukung dari regulasi pemerintah mengenai larangan bagi para konsumen lampu hemat energi untuk melakukan pembuangan sampah lampu pasca pakai langsung ke tempat sampah.

Proses pengecekan yang ketiga dapat dilihat dari tingkat jumlah lampu pasca pakai yang dapat diperbaiki pada saat tahap atau proses inspeksi. Apabila tingkat perbaikan dari komponen lampu pasca pakai rendah atau lebih banyak komponen yang tergolong cacat maka hal ini mengindikasikan masih adanya pola penanganan yang tidak tepat pada tahap sebelum proses inspeksi, yaitu pada proses pengumpulan kembali ataupun pemilahan. Proses pengumpulan kembali dan pemilahan harus menjamin keutuhan dari produk lampu pasca pakai, keutuhan tersebut dapat dilihat dari tidak terjadi kerusakan pada komponen bulb, electronic ballast, atau base. Selain itu, desain dari electronic ballast sebaiknya memiliki masa guna yang lama sehingga komponen komponen dalam electronic ballast pasca pakai 
Tabel 4: Tingkat Daur Ulang Maksimum

\begin{tabular}{|c|c|c|c|}
\hline Material & Massa(g) & $\begin{array}{c}\text { Tingkat Daur } \\
\text { Ulang }(\%)\end{array}$ & $\begin{array}{c}\text { Estimasi } \\
\text { Massa } \\
\text { Hasil Daur } \\
\text { Ulang }(\mathrm{g})\end{array}$ \\
\hline Kaca & 1,2 & 23,7 & 0,284 \\
\hline Yttrium & 1,37 & 0,9 & 0,012 \\
\hline Europium & 0,001 & 0,9 & 0,000009 \\
\hline $\begin{array}{c}\text { Polyethylene } \\
\text { Terepthalate } \\
\text { (PET) }\end{array}$ & 2,39 & 30 & 0,717 \\
\hline Cast Iron & 0,029 & 60 & 0,017 \\
\hline Kromium & 0,0002 & 60 & 0 \\
\hline $\begin{array}{c}\text { Aluminium } \\
\text { Oksida }\end{array}$ & 0,008 & 60 & 0,005 \\
\hline Timbal & 0,19 & 60 & 0,114 \\
\hline Tembaga & 0,402 & 60 & 0,241 \\
\hline Nikel & 0,003 & 60 & 0,002 \\
\hline Kuningan & 1,65 & 60 & 0,99 \\
\hline Semikonduktor & 127,268 & - & - \\
\hline $\begin{array}{c}\text { Printed Wiring } \\
\text { Board }\end{array}$ & 3,7 & - & - \\
\hline Merkuri & 0,004 & 10 & 0,0004 \\
\hline Gas Argon & 0,004 & - & - \\
\hline Gas Nitrogen & 0,119 & - & - \\
\hline Gas Oksigen & 0,159 & - & - \\
\hline Gas Hidrogen & 0,002 & - & - \\
\hline Gas Neon & 0,0004 & - & - \\
\hline Amonia & 0,13 & - & - \\
\hline Asam Nitrik & 7,9 & - & - \\
\hline Asam Sulfur & 1,67 & - & 62,046 \\
\hline Lem Resin & 4,5 & - & - \\
\hline Solder Paste & 0,3 & 60 & \\
\hline Corrugated \\
Board & 81 & 76,6 & \\
\hline Total Massa & 234 & & \\
\hline
\end{tabular}

masih dapat digunakan kembali sebagai komponen penyusun lampu yang baru pada proses remanufaktur.

Hasil dari proses remanufaktur dapat digunakan sebagai proses pengecekan keempat sebagai indikasi berjalannya sistem ini. Semakin banyak penggunaan komponen daur ulang maupun komponen hasil dari perbaikan dalam pembuatan produk lampu yang baru dapat dijadikan salah satu variabel pengecekan berjalannya sistem. Oleh karena itu, teknik remanufaktur juga memegang peranan penting dalam menghasilkan produk dengan kualitas dan fungsi yang sama halnya dengan produk yang dihasilkan dari hasil proses manufaktur.

\section{Kesimpulan}

Pola pembuangan lampu hemat energi yang tidak tepat dapat menimbulkan masalah bagi lingkungan dan kesehatan tubuh manusia. Hal itu disebabkan adanya kandungan merkuri dalam lampu hemat energi. Merkuri ini dapat terlepas ke lingkungan apabila komponen bulb mengalami kerusakan. Bila pola penanganan yang tidak tepat ini berlangsung terus menerus maka kemungkinan terjadinya proses akumu- lasi tersebarnya merkuri pada tanah di Kota Bandung akan melewati nilai ambang batas yang sudah ditentukan.

Siklus hidup lampu hemat energi yang saat ini bermula dari ekstraksi material, manufaktur, penggunaan, Tempat Pembuangan Sementara, dan Tempat Pembuangan Akhir diusulkan berdasarkan konsep Inverse Manufacturing menjadi ekstraksi material, manufaktur, penggunaan, pengumpulan kembali, pemilahan, inspeksi, perbaikan, remanufaktur, daur ulang, pemanfaatan untuk keperluan lain, dan pembuangan akhir.

Dengan adanya penerapan konsep Inverse Manufacturing dalam penanganan produk lampu hemat energi mendukung untuk tercapainya konservasi sumber daya alam dan energi serta menjaga lingkungan dan manusia di dalamnya tetap aman. Peranan dari konsumen, produsen, dan pemerintah diperlukan agar pola penanganan lampu yang tepat ini dapat terealisasikan.

\section{Daftar Pustaka}

Clarkson, T. W., Magos, L., \& Myers, G. J. (2003). The toxicology of mercury current exposures and clinical manifestations. The New England Journal of Medicine, 349:1731-7.

Kimura, F. (1999). Life cycle design for inverse manufacturing. International Symposium On Environmentally Conscious Design and Inverse Manufacturing EcoDesign. DOI : 10.1109/ECODIM.1999.747754.

Lardinois, I., \& Klundert, A., V., D. (1995). Plastic waste. Amsterdam, Belanda : TOOL Publications.

Li, Yadong \& Jin, Li. (2011). Environmental release of mercury from broken compact fluorescent lamps. Environmental Engineering Science, 28,1 5. DOI : 10.1089/ees.2011.0027.

Madu, C. N. (2004). Competing on Quality and Environment. United States of America : Chi Publishers.

Mirdat, Patadungan, Y., S., \& Isrun. (2013). Status logam berat merkuri $(\mathrm{Hg})$ dalam tanah pada kawasan pengolahan tambang emas di kelurahan Poboya, Kota Palu. Agrotekbis 1 (2) : 127134.

Sasaki, R., I. (1994). The impact of electronic ballast compact fluorescent lighting on power distribution system. Purdue University School of Electrical Engineering. 
Scholand, M. J., \& Dillon, H. E. (2012). Life cycle assessment of energy and environmental impacts of led lighting products Part 2 : led manufacturing and performance. Pacific Northwest National \& N14 Energy Limited.

Tunsu, C., Retegan, T., \& Ekberg, C. (2011). Sustainable processes development for recycling of fluorescent phosphorus powders-rare earths and mercury. Gothenburg, Swedia : Chalmers University of Technology.

Williams, P., T. (2005). Waste Treatment and Disposal. West Sussex, England: Wiley. 